\title{
Model Pembelajaran Techopreneur Meningkatkan Kemampuan Mahasiswa dalam Memulai Usaha di Universitas
}

\author{
John Roni Coyanda ${ }^{1)}$ \\ ${ }^{1)}$ Program Studi Sistem Informasi, Universitas Indo Gobal Mandiri \\ Jl. Jend.Sudirman No 629 Km 4 Palembang \\ Email :coyaaad@uigm.ac.id ${ }^{1)}$
}

\begin{abstract}
Technopreneur combining technology and entreprenur, Technopreneur is understanding the business of developing business with the ability to rely on science and technology, developed by the business Teknopreneur known as the business of technology. Business technology is developed with the occurrence of synergy between Teknopreneur as and business, University and Research as a new technology innovation center, and the Venture capitalist will fund the business. University in motivating the scholar to become the Businessman was very important in cultivating the number of businessmen. With the increase from the scholar's circle will reduce the increase in the number of unemployments in fact increased the number of fields on the work. His question was how the university side could make to Technopreneur. The role of his one it was explained by (Thomas Zimmerer) that one of the motive factors of the growth of entrepreneurship was entrepreneurship education. Moreover (Douglas A.Gray) suggested to begin efforts since early for example when still the lecture. Whereas the data in an empirical manner also was obtained through the research that was carried out to the student of the University about the factor most dominant motivated the alumnus to wirausahawan. Results of this research mentioned that the opportunity factor that pushed the dtudent and alumnus decided to become Technoprenur. With our success get help from the Student's Program entrepreneurs we formed Technopreurship Center,yang could help the interested student in an effort to in the IT field.
\end{abstract}

Keywords : Technopreneur, University

\begin{abstract}
ABSTRAK
Technopreneur merupakan gabungan teknologi dan wirausaha, Technopreneur mengembangkan bisnis dengan kemampuan untuk menerapkan ilmu pengetahuan dan teknologi, yang dikembangkan oleh usaha Teknopreneur yang dikenal sebagai bisnis dengan teknologi. Bisnis teknologi dikembangkan dengan adanya sinergi antara Teknopreneur dan bidang usaha, Universitas sebagai pusat inovasi teknologi baru, dan bidang usaha besar akan mendanai bisnis tersebut. Universitas dalam memotivasi sarjana untuk menjadi Pengusaha sangat penting dalam menumbuhkan jumlah pengusaha. Dengan bertambahnya dari peneliti dan usahanwan muda akan mengurangi peningkatan jumlah pengangguran bahkan meningkatkan jumlah bidang pada pekerjaan. Pertanyaannya adalah bagaimana pihak universitas dapat membuat Technopreneur. Peranannya dijelaskan oleh (Thomas Zimmerer) bahwa salah satu faktor pendorong pertumbuhan kewirausahaan adalah pendidikan kewirausahaan. Apalagi (Douglas A.Gray) menyarankan untuk memulai dari sejak dini misalnya saat masih proses perkuliahan. Sedangkan data secara empiris juga diperoleh melalui penelitian yang dilakukan kepada mahasiswa Universitas tentang faktor yang paling dominan memotivasi alumni untuk wirausahawan. Hasil penelitian ini menyebutkan bahwa faktor peluang yang mendorong mahasiswa dan alumni memutuskan untuk menjadi Technoprenur. Dengan kesuksesan kami mendapatkan bantuan dari para Program kreativias Mahasiswa, kami membentuk Technopreurship Center, yang dapat membantu mahasiswa yang tertarik dalam upaya di bidang TI
\end{abstract}

Kata kunci : Teknologi Wirausaha, Universitas 


\section{Pendahuluan}

Technopreneur adalah seorang wirausahawan yang paham teknologi, kreatif, inovatif, dinamis, berani tampil beda, menempuh jalan yang belum dijelajahi dan sangat bersemangat dengan pekerjaannya (Nasution et al. 2007). Individu yang memiliki sifat teknopreneurial menerima tantangan dan berusaha untuk menjalani hidup mereka dengan kesuksesan yang lebih besar. Ciri-ciri kepribadian teknopreneur termasuk tidak takut untuk gagal, menganggap kegagalan sebagai pengalaman belajar, dan mahir dalam memandang berbagai hal secara berbeda, dan selalu mencari tantangan berikutnya (Cereijo 2002; Depositario et al. 2011). Technopreneur mengoperasikan bisnis secara berbeda dari mereka yang berada dalam tatanan ekonomi yang ada dengan mengoptimalkan penggunaan teknologi untuk berinovasi produk dan layanan baru. Implikasinya adalah penciptaan bentuk organisasi baru dan eksploitasi bahan baku baru. Teknologi tidak hanya tentang teknologi tinggi atau hal-hal teknis, tetapi juga dapat merujuk pada aplikasi manusia dari pengetahuan yang bermanfaat yang dapat bermanfaat bagi masyarakat (Drucker 1985; Ibrahim et al. 2015). Kombinasi teknologi dan keterampilan kewirausahaan akan menghasilkan seorang technopreneur. Technopreneurs berarti seseorang yang menggunakan teknologi sebagai bagian dari model bisnis mereka. Technopreneur melibatkan orang-orang yang membuat atau menemukan bisnis berbasis teknologi mereka sendiri dengan mengenali peluang dan mengatur sumber daya (Ibrahim et al. 2015; Yudha 2010). Sementara itu, technopreneurship adalah hasil dari proses sintesis dan rekayasa ulang di masa depan dengan menggabungkan pengetahuan dalam teknologi dan keterampilan wirausaha untuk menciptakan model bisnis yang baru dan serbaguna. Menurut Cereijo (2002), technopreneurship yang menggabungkan kecakapan teknologi dan keterampilan kewirausahaan menjadi sumber nyata kekuatan dalam ekonomi berbasis pengetahuan. Dengan demikian, Nasution et al. (2007) berpendapat bahwa technopreneurs berkembang sangat dituntut dalam tatanan ekonomi saat ini.

Pada era digital saat ini pemerintah menaruh perhatian yang tinggi dalam mengembangkan Techopreneur untuk mahasiswa di perguruan tinggi di Indonesia,. Oleh karena itu setiap universitas di Indonesia didorong untuk memiliki mata kuliah dan kurikulum yang banyak menitik beratkan kegiatan kewirausahaan dari dasar usaha dan tingkatan lainya dengan mengkombinasikan dengan teknologi IT, untuk memfasilitasi pengembangan invensi dan inovasi antara mahasiswa yang berpotensi untuk menjadi tenaga yang kompeten di bidangnya. Selain itu, harapan bahwa proses inkubasi bisa mengembangkan semangat kewirausahaan di kalangan siswa dan mendorong mereka untuk menggunakan teknologi sebagai media dalam melaksanakan bisnis mereka. Untuk itu diharapkan ada model Technopreneur Center (TC) yang bisa membantu pihak kampus untuk memulai kegiatan ini dari merubah mindset dan menjalankan kegiatan mahasiswa untuk memulai kegiatana untuk ke tahap berikutnya. Perananan labarotorium dan mata kuliah kewirasusahaan dikampus sangat menentukan dalam mengkolaborasikan ilmu IT untuk di kembangkan dalam bidang usaha berbasis digital.

Aktivitas utama dalam membangun Model pembelajaran technopreneur ini adalah adalah mentoring dalam kegiatan perkuliahan di mulai dari pembekalan teori usaha, ide usaha, peluang usaha, menyeleksi ide atau solusi teknologi yang potensial dalam memecahkan masalah yang ada di mahasiswa, perlunya kelompokkelompok usaha sesuai bidang dan jenis, pemanfaatan teknologi IT juga berperan besar dalam penerapan bidang usaha ini, dengan teknologi yang tinggi di dukung kemampuan dalam mencoding bisa menjadikan kekuatan besar dalam pengelolaan technopreneur ini.

Mendukung terwujudnya hasil teknologi itu dengan memberikan fasilitasi pada ide atau solusi terpilih. Incubation Center yang diberikan dalam bentuk: pengembangan ide menjadi produk yang teruji, perkembangan teknologi yang sudah menyentuh semua kalangan berdampak perlunya adanya pemuda-pemuda yang berjiwa usaha untuk menciptkan peluang ini, semua usaha sekarang sudah menggunakan media digital dalam promosi dan transaksi usaha.

Sebagian besar pendorong perubahan, inovasi dan kemajuan suatu adalah para wirausahawan muda, youtuber muda, digital kreatif, Wirausahawan muda adalah seseorang yang menciptakan sebuah bisnis yang berhadapan dengan resiko dan ketidakpastian bertujuan memperoleh profit dan mengalami pertumbuhan dengan cara mengidentifikasi kesempatan dan memanfaatkan sumber daya yang diperlukan. Dewasa ini banyak kesempatan untuk berwirausaha bagi setiap orang yang jeli melihat peluang bisnis tersebut. Peluang TC dapat mendukung kesejahteraan masyarakat yaitu menghasilkan nilai income yang yang nyata. Technologi dan entrepreneurship di berbagai industri membantu dalam hal menambahkan pilihan pekerjaan bagi masyarakat serta memberikan banyak pilihan barang dan jasa bagi konsumen baik dalam maupun luar negeri. by Consortium for Entrepreneurship Education, (2004).

\section{Pembahasan}

Dalam penelitian teori yang digunakan model yang relevan dengan subjek penelitian, serta teori-teori dan model yang mendukung tentang penelitian ini . theoris dan model yang akan dieksplorasi dan digunakan di seluruh penelitian dibahas dalam sub bagian berikut :

\section{A. Technology Based Firm}

TE secara langsung terkait dengan perusahaan yang berbasis teknologi baru. Menurut, Hamilton dan Kern (2001), untuk menjalankan bisnis ICT, mereka menyarankan beberapa dimensi berikut untuk pengusaha untuk struktur organisasi mereka:

1. Orang-orang - setiap individu dalam organisasi memiliki kemampuan tertentu, dan keterampilan ini biasanya diukur terhadap matrik kinerja formal 
maupun informal yang mengarah ke imbalan (kompensasi) sebagai insentif untuk kinerja masa depan;

2. Proses-proses dan metodologi yang digunakan oleh orang-orang dalam organisasi dan

3. Teknologi - keterampilan khusus dan alat yang digunakan orang dalam organisasi untuk melaksanakan fungsi-fungsi bisnis organisasi.

Hamilton dan Kern juga menambahkan bahwa konsep-konsep ini berlaku bagi setiap organisasi TE, dan secara khusus berlaku bagi organisasi pengembangan perangkat lunak, terlepas dari ukuran.Organisasi bisnis ICT struktur dimensi seperti yang disarankan oleh Hamilton dan Kern .

Organisasi bisnis ICT struktur dimensi seperti yang disarankan oleh Hamilton dan Kern diilustrasikan pada Gambar 1..

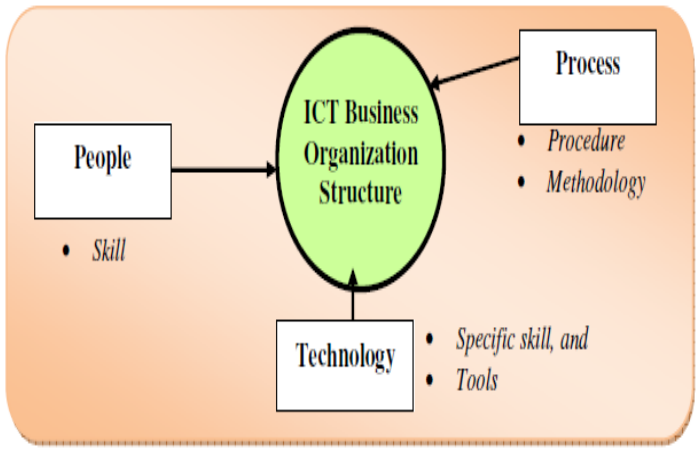

Gambar 1. The dimension of ICT business organization structure (Adapted from Hamilton and Kern, 2001)in Sahadah (2010).

\section{B. S-TEK Models}

Ada empat faktor utama dan enam faktor pendukung, dapat mendorong seseorang untuk menjadi dan bertahan sebagai seorang pengusaha teknologi di pasar. Keempat faktor kunci adalah orang, pengetahuan bisnis dan manajemen, keterampilan teknis dan dukungan alat, dan strategi komersialisasi. Sahadah juga telah mencatat bahwa keempat faktor kunci juga perlu didukung oleh enam faktor yaitu kebijakan pemerintah dan dukungan, dukungan finansial, pengalaman bisnis, faktor ekonomi, peluang pasar dan dukungan keluarga. Model Sahadah di TE faktor kunci sukses, yang juga dikenal sebagai STEK Model ( Adapted to Sahadah 2010).

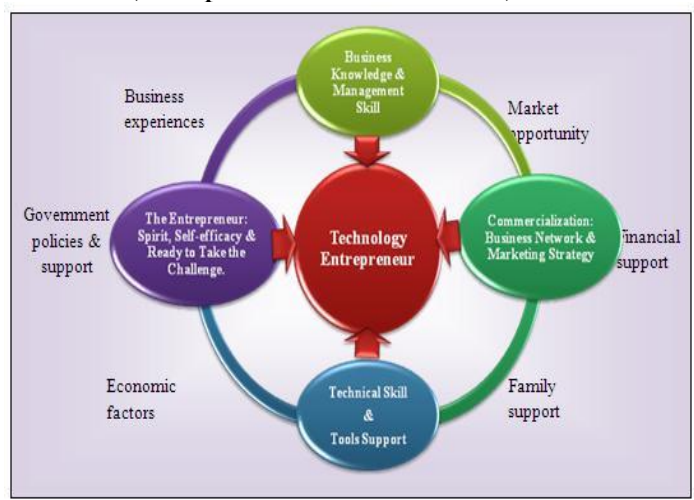

Gambar 2. S-TEK Model (Adopted from Sahadah, 2010)
C. Model Proses, Kreativiti dan Inovasi

Scapher dan Volery (2004) telah mengemukakan Model Proses, Kreativiti dan Inovasi dalam bidang kewirausahaan. Mereka mengatakan terdapat hubungan di antara kreativiti, inovasi dan kewirausahaan sebagai satu model proses.

Dalam model ini, inovasi mempunyai hubungan yang jelas di antara teknologi dan pemasaran

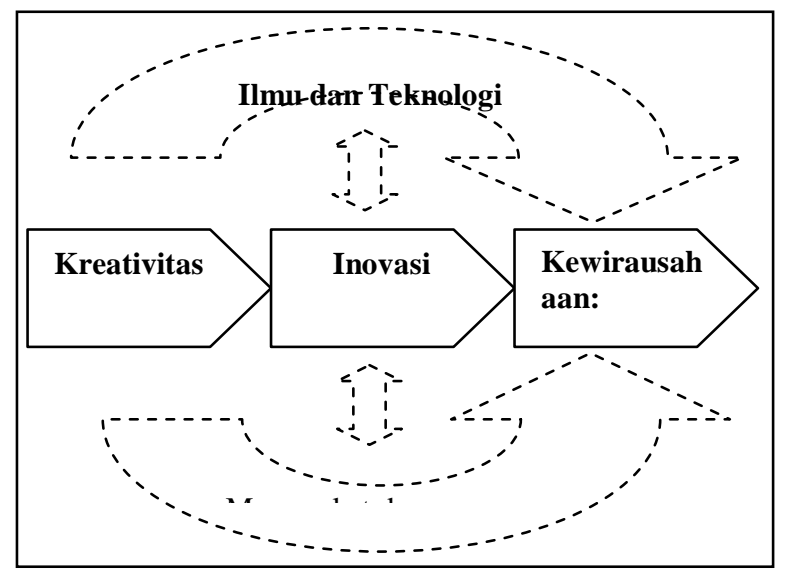

Gambar 3. Model Proses, Kreativiti dan Inovasi dalam bidang kewirausahaan

Pada tahap ini Mahasiswa yang mau mengembangkan usaha mereka yang harus mempunyai pengetahuan tentang Wirausaha sebagai usaha mereka dan berusaha untuk mengembangkan usaha yang mereka geluti. Setiap calon Wirusausaha yang berada pada tahap masing-masing perlu mengfokuskan kepada hasil yang ditetapkan pada setiap tahap dan dalam waktu yang sama berusaha menjalin hubungan dengan para wirausaha yang lain Shaw E., O'Loughlin A. \& McFadzean E. (2005).

\section{Model Learning Community}

Model ini dalam proses belajar mengajar, seorang tutor harus memiliki strategi agar siswanya dapat belajar secara efektif, mengenai pada tujuan yang diharapkan. Salah satu langkah untuk memiliki strategi itu ialah harus menguasai teknik penyajian atau biasanya disebut dengan metode mengajar. Kata kunci dari metode learning community adalah berbicara dan berbagi pengalaman dengan oranglain, bekerjasama dengan orang lain untuk menciptakan pembelajaran yang lebih baik dibandingkan dengan belajar sendiri. Hasil belajar secara bersama-sama merupakan hasil belajar bisa diperoleh dengan sharing antar teman, antarkelompok, dan antara yang tahu kepada yang tidak tahu, baik di dalam maupun di luar kelas. Karena itu pembelajaran yang dikemas dalam diskusi kelompok dengan anggota yang heterogen dan jumlah yang bervariasi sangat mendukung komponen model pembelajaran learning community menurut., Nurhadi, dkk. Pembelajaran Kontekstuacontextual teaching and learning (Malang: UM pres. 2004), h. 21 


\section{E. Usulan Model Technopreneur Center}

Metodologi dari penelitian ini mengunakan hasil kuesioner dan wawancara dengan mahasiswa dan mentor bidang usaha IT dan perusahaan yang mengunakan usaha bidang digital baik dari industri maupun usaha rumahan maka, model ini cocok untuk menciptkan young techoprenuer ini bisa menjadi salah satu acuan untuk menciptakan ide kreativitas, selain proposal yang bagus di tuntut kemampuan baik skill maupun pengetahuan baik bidang kewirausahaan dan teknologi. Selain itu data yang di ambil didasarkan pada tinjauan pustaka, memperoleh dan mensintesis data, dan informasi dari temuan penelitian dari penelitian saya sebelumnya. Dari dokumen yang dianalisis meliputi jurnal sebelumnya, buku referensi, laporan, prosiding, dan makalah proyek. Peneliti menganalisis, mensintesiskan temuan sekunder ini dan membuatnya lebih bermakna untuk tujuan topik penelitian.

Model ini juga bertujuan untuk meningkatkan kerjasama antara lembaga dan pihak terkait menciptakan peluang usaha ini bisa meningkatkan kreativitas dan ide dalam membuat sebuah project dan diharapkan muncul usaha-usaha baru. Dan munculah mahasiswa muda yang berwirausaha dan berteknologi dalam menjalankan usaha baru.menurut, Scherer, R.F., J.D. Brodzinsky, F.A. Wiebe, 1991;

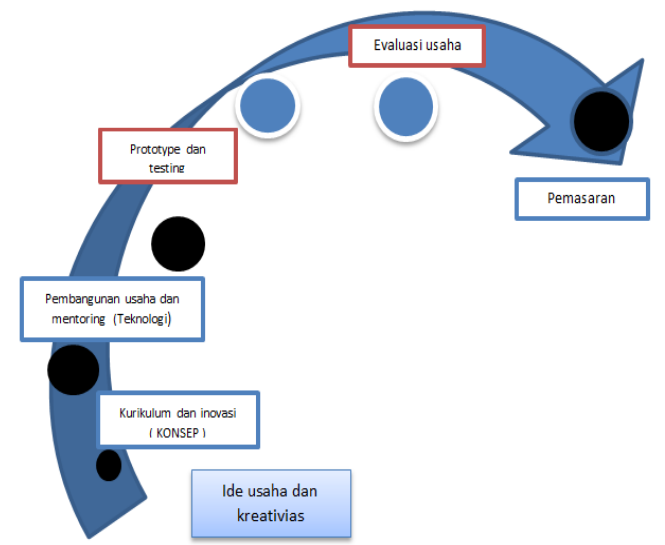

Gambar 4. Model Technopreneur Center (MTC) untuk proses inkubator universitas di Indonesia

Model TC diatas terdiri atas 3 Fhase yang secara berkesinambungan saling berkaitan untuk mencapai tujuan usaha yang di buat selama perkuliahan :

1. Phase Konsep

2. Phase Teknology

3. Phase Pemasaran

Model ini juga di buat setelah menganalisa data dari beberapa PTS dan Mahasiswa yang menjalankan usaha IT. dan mahasiswa yang sedang kuliah mata kuliah kewirausahan, praktikum kewirausahan dan technoprenuer, mahasiswa di tuntut untuk mengenal dan mengerti tentang bagaiamana :

1. Memulai ide dan kreativitas,

2. Kurikulum dan inovasi

3. Menciptkan peluang,

4. Ide bersama di kumpulkan dari sesama kelompok,

5. Pembuatan rencana / design usaha
6. Evaluasi usaha

7. Barnding dan marketing

8. Pembuatan laporan

Dalam kegiatan usaha, ide kreatif dengan kemampuan di bidang IT, support dari pihak eksternal, baik pemerintah, perguruan tinggi dan industry ini akan mendapatkan hasil project usaha yang berkualitas, harus melalui tahapan-tahapan. Secara nyata model MTC ini mengusulkan kegiatan sistematis untuk mengembangkan usahawan muda berbasis IT melalui proses perkuliahan dan incubator di perguruan tinggi di Indonesia. Kegiatan utama adalah mulai dari mencari anggota, memilih ide bisnis potensial dan rencana bisnis. Untuk sampai ke tingkat ini, semua Peserta dan Mahasiswa di dorong untuk mengajukan ide bisnis dan rencana bisnis. Pilihhan usaha dan ide bisnis yang baik akan proses secara bersama-sama untuk mengembangkan ide kreatif dalam meningkatkan usaha dan pelatihan; perlunya Jaringan bisnis, Dukungan industri dan juga dukungan finansial sangat membantu kegiatan ini berjalan dengan baik.

Tujuan dan model pembelajaran Teknopreneurship adalah:

1. Menyiapkan sarana utnuk mahasiswa, untuk membangun bisnis mandiri dalam bidang TC.

2. Mempercepat proses pembelajaran TC dalam menerapakan usahabisnis.

3. Bagaimana untuk Menciptakan jaringan dan kemitraan untuk menargetkan TC

4. Bantuan faslitas dan modal untuk mendorong pembukaan lapangan kerja baru.

5. Untuk Menciptakan peluang untuk transfer teknologi. (Shapero, A., L. Sokol, 1982)

Dari hasil penelitian ini akan di lanjutkan bagaimana mengimplementasikan Framework Inkubator di Universitas dan lembaga-lembaga yang akan membuat pusat Incubator dalam menjalankan Usaha yang berbasis teknologi dan IT. Dan diharapakan muncul ide-ide project Usaha yang muncul dari kalangan akademisi dan mahasiswa.,Sehingga akan muncul Mahasiswa muda yang berwirausaha dengan Teknologi.

\section{Kesimpulan}

Penelitian ini untuk mengusulkan model pembelajaran TC melalui proses pembuatan kurikulum yang bertujuan untuk menyusun kerangka dasar pemikiran mahasiswa dalam memulai usaha, yang memberikan nuasa pembuatan usaha dan bisnis langsung praktek dengan membekali mereka dengan kompetensi bidang usaha dan IT dengan mata kuliah sesuai bidangnya kewirausahan, praktikum, technoprenuer di kampus, sehingga bisa di pergunakan oleh mahasiswa dalam meningkatkan kemampuan skill dan pengetahuan dalam membuat sebuah usaha dan kreativitas. Melalui pendekatan penelitian dan survey ke mahasiswa dan mentor, penulis telah membawa bersama-sama pengetahuan dari teori dan model TC serta wawancara mendalam dengan informan kunci. Studi kualitatif ini memberikan para peneliti dengan informasi menyeluruh yang sangat berguna dalam mengembangkan kerangka 
model yang diajukan. Dengan 3 phase utama konsep, teknologi, dan marketing dan di support lingkungan internal, lingkungan eksternal, dan proses pengembangan, kerangka model ini diharapkan dapat bermanfaat bagi mahasiswa, diharapkan muncul generasi-generasi muda yang mampu merubah dunia dan bisa meningkatkan peluang usaha, membuka lapangan pekerjaan yang luas dan mengembangkan TC di Indonesia.

\section{Daftar Pustaka}

Aldrich, H. \& Zimmer, C. 1986. Entrepreneurship Through Social Networks, in Donald Sexton and Raymond Smilor, The Art and Science of Entrepreneurship, New York: Ballinger.

Bruyat, C. \& Julien, P.A. 2000. Defining the field of research in entrepreneurship, Journal of Business Venturing, Vol. 16 No. 2, pp.165-80.

Consortium for Entrepreneurship Education, 2004. Nurturing the Entrepreneurial Spirit. Retrieved at http://www.entred.org/Standards Toolkit/nurturing.htm

Schaper M. \& Volery T. 2004. Entrepreneurship And Small Business. A Pacific Rim Perspective. John Wiley. Australia.

Shaw E., O'Loughlin A. \& McFadzean E. 2005. Corporate entrepreneurship and innovation part 2: a role and process-based approach, European Journal of Innovation Management, Vol.8, No. 4. pp 393-408.

Liles, P.R., 1974. New Business Ventures and the Entrepreneur, Homewood, Irwin.

Linan, F., 2004. Intention-Based Models of Entrepreneurship Education, Napoly: 14th Annual IntEnt Conference.

Nurhadi, dkk. Pembelajaran Kontekstuacontextual teachingand learning (Malang: UM pres. 2004), h. 21

Sahadah, A., 2010. Technology Entrepreneur Development at Graduate Training in Malaysian Institute of Higher Learning. Doctoral Dissertation. Univeriti Teknologi Malaysia

Schaper M. \& Volery T. 2004. Entrepreneurship And Small Business. A Pacific Rim Perspective. John Wiley. Australia.

Scherer, R.F., J.D. Brodzinsky, F.A. Wiebe, 1991. "Examining the relationship between personality and entrepreneurial career reference", Entrepreneurship and Regional Development, vol 3, pp. 195-206.

Sexton, D.L., N.B. Bowman, 1984. "Entrepreneurship education: Suggestions for increasing effectiveness", Journal of Small Business Managemen, vol 22(2), pp. 18-25.

Shapero, A., L. Sokol, 1982. Social Dimention of Entrepreneurship, Sexton, Kent, C.A. 